\title{
MUMI Expression versus Hans Algorithm to Predict Prognosis in Indonesian Diffuse Large B-Cell Lymphoma Patients Receiving R-CHOP
}

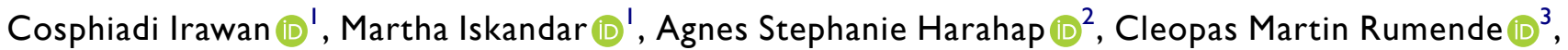 \\ Maria Francisca Ham $\mathbb{D}^{2}$ \\ 'Hematology and Medical Oncology Division, Internal Medicine Department, Dr. Cipto Mangunkusumo Hospital, Faculty of Medicine, Universitas \\ Indonesia, Jakarta, 10430, Indonesia; ${ }^{2}$ Anatomical Pathology Department, Dr. Cipto Mangunkusumo Hospital, Faculty of Medicine, Universitas \\ Indonesia, Jakarta, 10430, Indonesia; ${ }^{3}$ Internal Medicine Department, Dr. Cipto Mangunkusumo Hospital, Faculty of Medicine, Universitas Indonesia, \\ Jakarta, 10430, Indonesia
}

Correspondence: Martha Iskandar, Tel +628I61924095, Email marthaiskandar@gmail.com

Background: Treatment response in diffuse large B-cell lymphoma (DLBCL) is heterogenous. The Hans algorithm (using 30\% cutoffs for CD10, BCL6, and MUM1 protein expression) has been the most favored method to categorize DLBCL into germinal center B-cell (GCB) and non-GCB subtypes in order to predict prognosis. However, the algorithm's ability to prognosticate is not always consistent.

Methods: This retrospective cohort study was conducted on DLBCL patients receiving R-CHOP therapy at Dr. Cipto Mangunkusumo Hospital, Jakarta from 2014 to 2017. We aimed to compare the prognostic value of Hans algorithm as well as the protein levels of CD10, BCL6, MUM1, and Ki67 at different cut-offs. Ninety-two patients were classified based on Hans algorithm and various proteins at different cut-off values were analyzed with regard to event-free survival at 24 months using survival analysis. The cut-off values were then compared using receiver operating characteristic curves.

Results: A significant survival difference was observed with MUM1 expression cut-off of 50\% or more (log rank $\mathrm{p}=0.035)$. CD10, BCL6, Ki67, and Hans algorithm showed AUCs below or near 0.5 (0.405, 0.436, 0.498, and 0.413, respectively), whereas MUM1 showed an AUC of 0.835 , in predicting events within 24 months. MUM-1 cut-off of $70.5 \%$ yielded an optimal trade-off for sensitivity and specificity.

Conclusion: MUM1 expression of $50 \%$ or more can help predict prognosis in DLBCL patients receiving R-CHOP therapy and can be considered as for use as a single marker to predict prognosis.

Keywords: DLBCL, RCHOP, MUM1, Hans algorithm, prognosis

MeSH Terms: lymphoma, large B-cell, dIffuse, MUM1 nucleosome-binding protein, human, antineoplastic combined chemotherapy protocols/adverse effects, rituximab/therapeutic use, retrospective studies, prognosis

\section{Introduction}

Diffuse large B-cell lymphoma (DLBCL) is the most common lymphoid malignancy in adults. DLBCL accounts for $30-40 \%$ of all non-Hodgkin lymphomas in Western countries, and even reaches $40-60 \%$ in some Far East countries. ${ }^{1-5}$ DLBCL is a heterogenous disease, consisting of different biological and clinical properties, as well as responses to treatment. ${ }^{4}$ For these reasons, many predictive models have been proposed to stratify the prognosis of DLBCL.

The International Prognostic Index (IPI) score has been widely used as a clinical tool to predict outcome in DLBCL patients receiving standard CHOP (cyclophosphamide, doxorubicin, vincristine, and prednisone) chemotherapy. However, its performance has declined in the Rituximab era. ${ }^{6}$ On the other hand, gene expression profiling (GEP) using cDNA microarray analysis has succeeded in identifying two distinct subtypes of DLBCL that differ in prognosis, albeit in the addition of Rituximab. According to GEP, the two subtypes are distinguished by different genes involved in 
a discrete stage of B-cell development, and known as germinal center B-cell (GCB) and non-GCB, the former of which consistently has better prognosis. ${ }^{7-9}$

Despite the excellent prognostic performance by GEP, it is not routinely applied because of its high cost and lack of availability. Several immunohistochemical (IHC) algorithms have been validated to differentiate between GCB and nonGCB subtypes based on different combinations of marker proteins. ${ }^{10}$ Using CD10 and BCL6 as GCB markers and MUM1 for a non-GCB marker, Hans classification has been the most favored algorithm to predict prognosis in DLBCL patients. ${ }^{11}$ However, a systematic review in 2017 found that Hans algorithm was unable to differentiate outcomes between those two subtypes. ${ }^{12}$ A prognostic study by $\mathrm{Oh}$ et al, nevertheless, found that various marker protein cut-off levels, instead of a uniform $30 \%$ cut-off, generated different prognoses. ${ }^{13}$ Each marker protein has its own role in DLBCL pathogenesis and might yield specific clinical information. ${ }^{13-19}$

Another renowned protein, Ki67, has been firmly established as a prognostic factor in cancer patients. ${ }^{20,21}$ In DLBCL, the most significant differences in overall survival occurred in cut-offs of $70 \%$ or more, however, predicting prognosis is still inconclusive. $^{22-25}$

Here we analyzed the prognostic role of Hans algorithm, as well as marker protein levels of CD10, BCL6, MUM1, and Ki67 in DLBCL patients who were treated with R-CHOP.

\section{Methods}

This retrospective cohort study was conducted at Dr. Cipto Mangunkusumo Hospital, a tertiary national referral hospital in Jakarta, Indonesia. Ethical approval was obtained from The Ethics Committee of the Faculty of Medicine, University of Indonesia (approval No. KET-493/UN2.F1/ETIK/PPM.00.02/2020). Patients' consent was not needed by our institutional ethics committee due to secondary analysis of existing data and no risk to subjects, all the data was anonymized and maintained with confidentiality and patients were treated in compliance with the Declaration of Helsinki. All diagnoses and levels of protein expression were confirmed by two hemato-pathologists (ASH and MFH).

Table I Clinical and Molecular Characteristics of DLBCL Patients

\begin{tabular}{|l|c|}
\hline Variables & No. of Patients (\%) \\
\hline Gender ( $\mathrm{n}=92)$ & $44(48)$ \\
Male & $48(52)$ \\
Female & \\
Age ( $\mathrm{n}=92$; median 5I.5 years, range I8-79 years) & $76(82)$ \\
$\leq 60$ years & $16(18)$ \\
$>60$ years & $57(85)$ \\
IPI ( $\mathrm{n}=67)$ & $10(15)$ \\
Low (score 0-2) & \\
High (score 3-5) & $45(49)$ \\
Protein expression (n=92) & $59(64)$ \\
CDI0 (30\% cut-off) & $85(92)$ \\
BCL6 (30\% cut-off) & $66(7 \mathrm{I})$ \\
MUMI (30\% cut-off) & \\
Ki67 (70\% cut-off) & $46(50)$ \\
Subtype based on Hans algorithm (n=92) & $46(50)$ \\
GCB & \\
Non-GCB & $44(48)$ \\
Event within 24 months ( $=92)$ & $40(43)$ \\
Yes & $8(9)$ \\
No & \\
No information & \\
\hline
\end{tabular}


Of the 109 adult DLBCL patients diagnosed between 2014 and 2107 and who received R-CHOP chemotherapy, 17 patients were excluded because of other conditions such as HIV-associated lymphoma, primary CNS (central nervous system) lymphoma, history of indolent lymphoma, or primary mediastinal large B-cell lymphoma.

Paraffin block of tissue was sliced by $3 \mu \mathrm{m}$ thickness, and was deparaffinized using xylol three times, each for 5 minutes, and then rehydrated using decreased alcohol concentration (ethanol, $96 \%$ alcohol and then $70 \%$ alcohol). A pre-treatment with antigen retrieval procedure was then done before further incubated using primary antibody of CD10, BCL6, MUM1, Ki67 (Leica Biosystems Newcastle Ltd, UK) for 60 minutes. Diamino Benzidine Tetrahydrochloride (DAB) was used for incubation, and then counterstained was done using Hematoxylin Mayer. Bluing was done using lithium carbonate before dehydrated using increasing alcohol concentration (70\% alcohol, $96 \%$ alcohol, ethanol).

Immunohistochemical stained slides of the ninety-two patients were assessed for percentage of CD10, BCL6, MUM1, and Ki67 protein expression using Image ${ }^{\circledR}$ software. The intensity of staining was not assessed because paraffin block processing might affect variability, as mentioned by Hans et $\mathrm{al}^{11}$ and de Jong et al. ${ }^{26}$ Event-free survival at 24 months (EFS 24) was calculated from the date of initial R-CHOP therapy to the date of the event or last follow-up visit. Disease progression, relapse, second-line treatment, any unplanned treatment, or death by any cause within 24 months were considered to be events, and were verified through medical records or death certificates. Patients with incomplete medical record data were contacted by telephone or home visits.

Kaplan-Meier survival analyses of EFS at 24 months and proteins at 10\% incremental cut-offs, Hans classification, as well as age, gender, and IPI category were carried out with SPSS software ver 23. The survival curves between subgroups were compared using log rank test. Cox Regression was used to evaluate the association of GCB classification, CD10, BCL6, MUM1, and Ki67 expression with event 24 months. The performance of Hans algorithm and each protein level, age, gender and IPI category were then analyzed by receiver operating characteristic (ROC) curves.

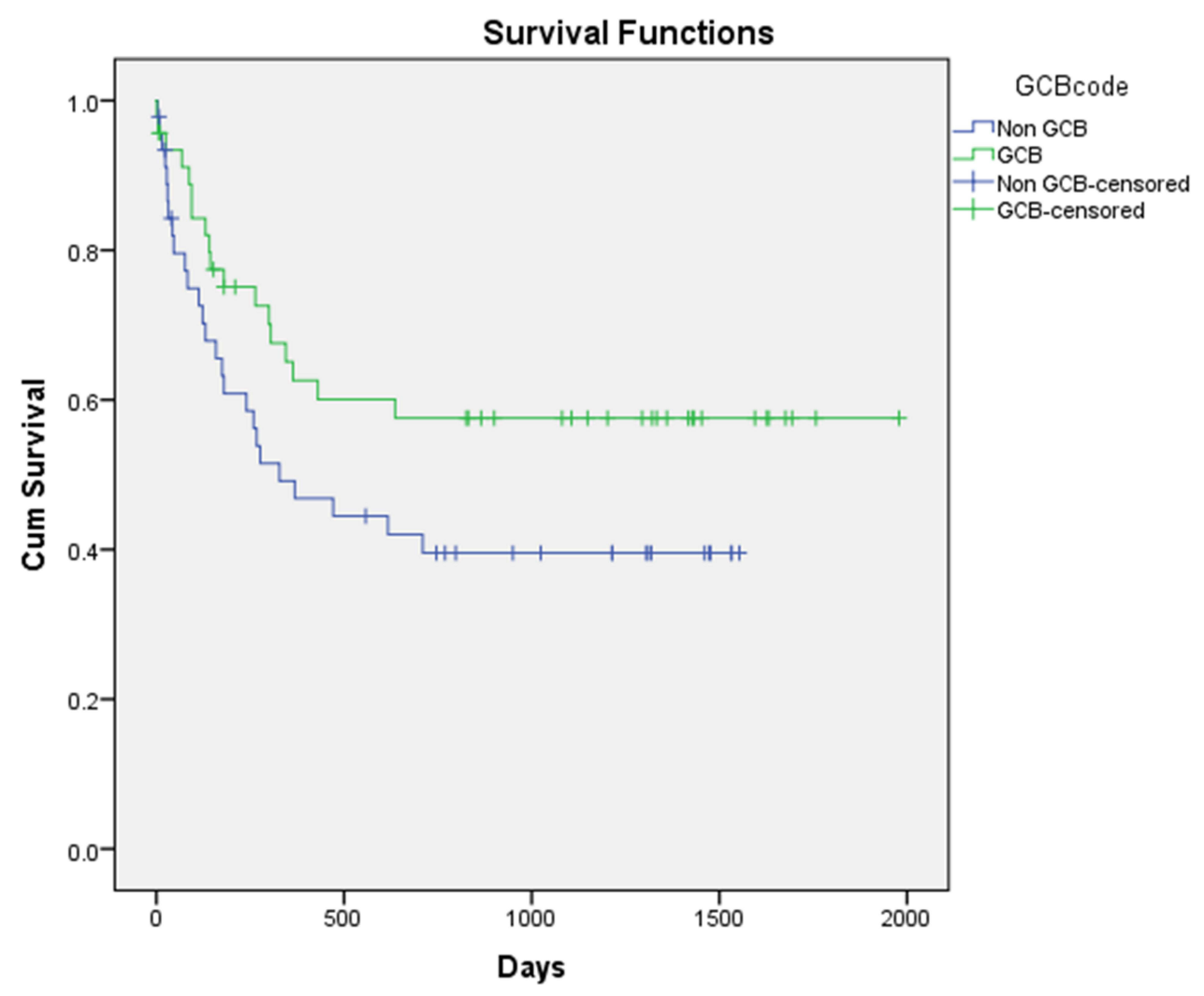

Figure I Kaplan-Meier survival curve of GCB (I) vs non-GCB (0) subtypes (log rank $p=0.08$ ). 

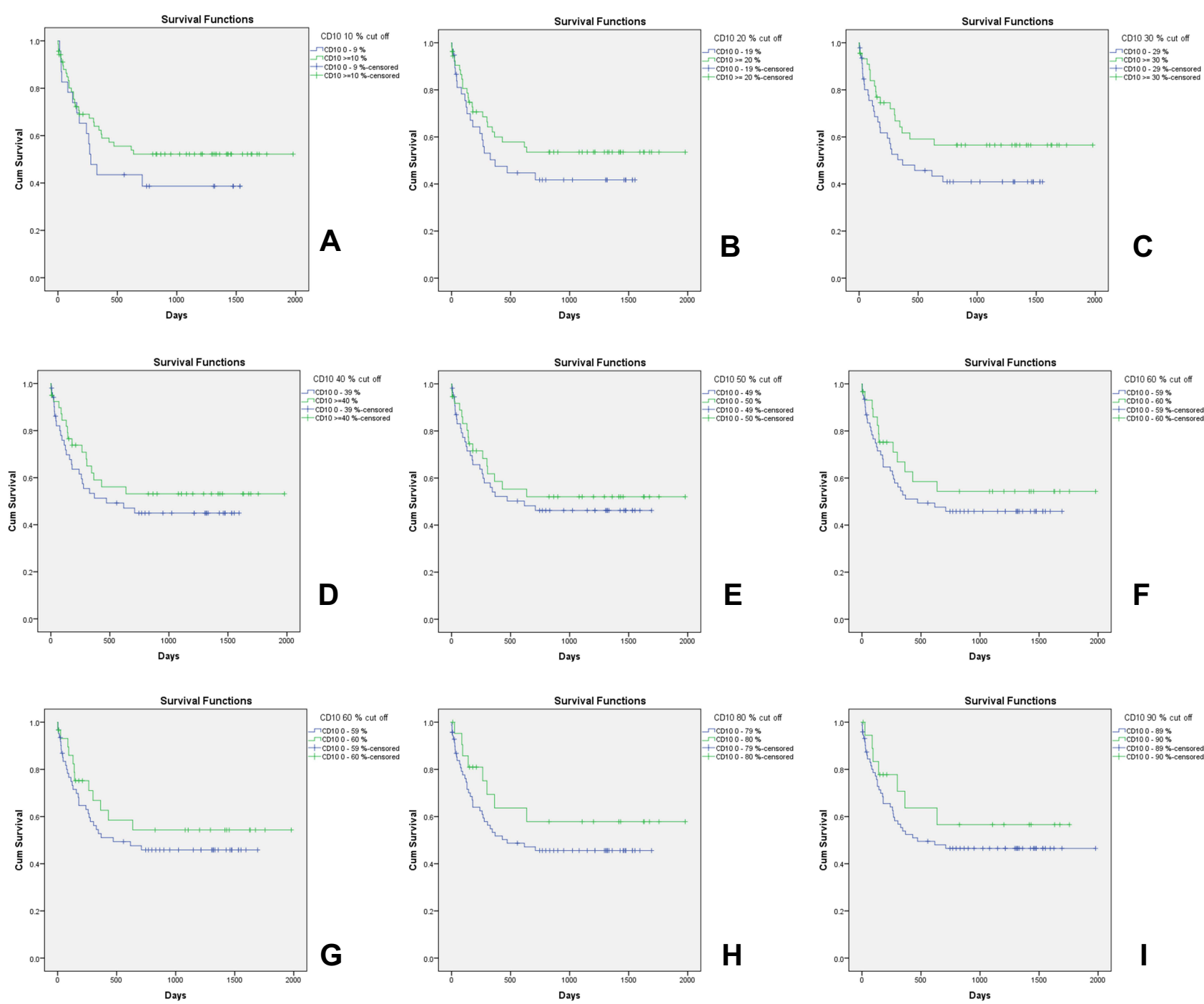

Figure 2 Kaplan-Meier survival curves of CDI0 at 10\% cut-off increments (A) 10\% cut-off (log rank $p=0.274)$ (B) $20 \%$ cut-off $(\log$ rank $p=0.270)($ C) $30 \%$ cut-off (log rank $p=0.127)(\mathbf{D}) 40 \%$ cut-off $(\log$ rank $p=0.370)(\mathbf{E}) 50 \%$ cut-off $(\log$ rank $p=0.546)(\mathbf{F}) 60 \%$ cut-off $(\log$ rank $p=0.383)(\mathbf{G}) 70 \%$ cut-off $(\log$ rank $p=0.273)(\mathbf{H}) 80 \%$ cut-off (log rank $p=0.253)($ I) $90 \%$ cut-off (log rank $p=0.370)$.

\section{Results}

\section{Patient Characteristics}

The characteristics of the 92 DLBCL patients treated with R-CHOP are listed in Table 1. Only 67 patients had complete IPI scores. During the average follow-up of 655 days and 60,240 person-days observation, 44 events (48\%) occurred in the 92 patients who were treated with R-CHOP.

\section{Analysis of Hans Algorithm and EFS24}

Of the 92 cases, positive CD10, BCL6, MUM1 expression was seen in 45 (49\%) cases, 59 (64\%) cases, and 85 (92\%) cases, respectively. Using Hans algorithm, 46 (50\%) cases were categorized with the GCB subtype. Kaplan-Meier survival analysis showed nearly significant difference in EFS24 between the GCB and non-GCB subtypes $(60.86 \%$ vs $43.48 \%$, respectively; $\log$ rank $\mathrm{p}=0.08$ ) (Figure 1).

Using Kaplan-Meier survival analysis on 92 patients, EFS24 and 10\% cut-off increments of each protein (CD10, BCL6, MUM1, Ki67) were analyzed. No significant differences in EFS24 between subgroups were revealed for CD10, BCL6, and Ki67 expression at the various cut-offs $(10 \%, 20 \%, 30 \%, 40 \%, 50 \%, 60 \%, 70 \%, 80 \%$, and 

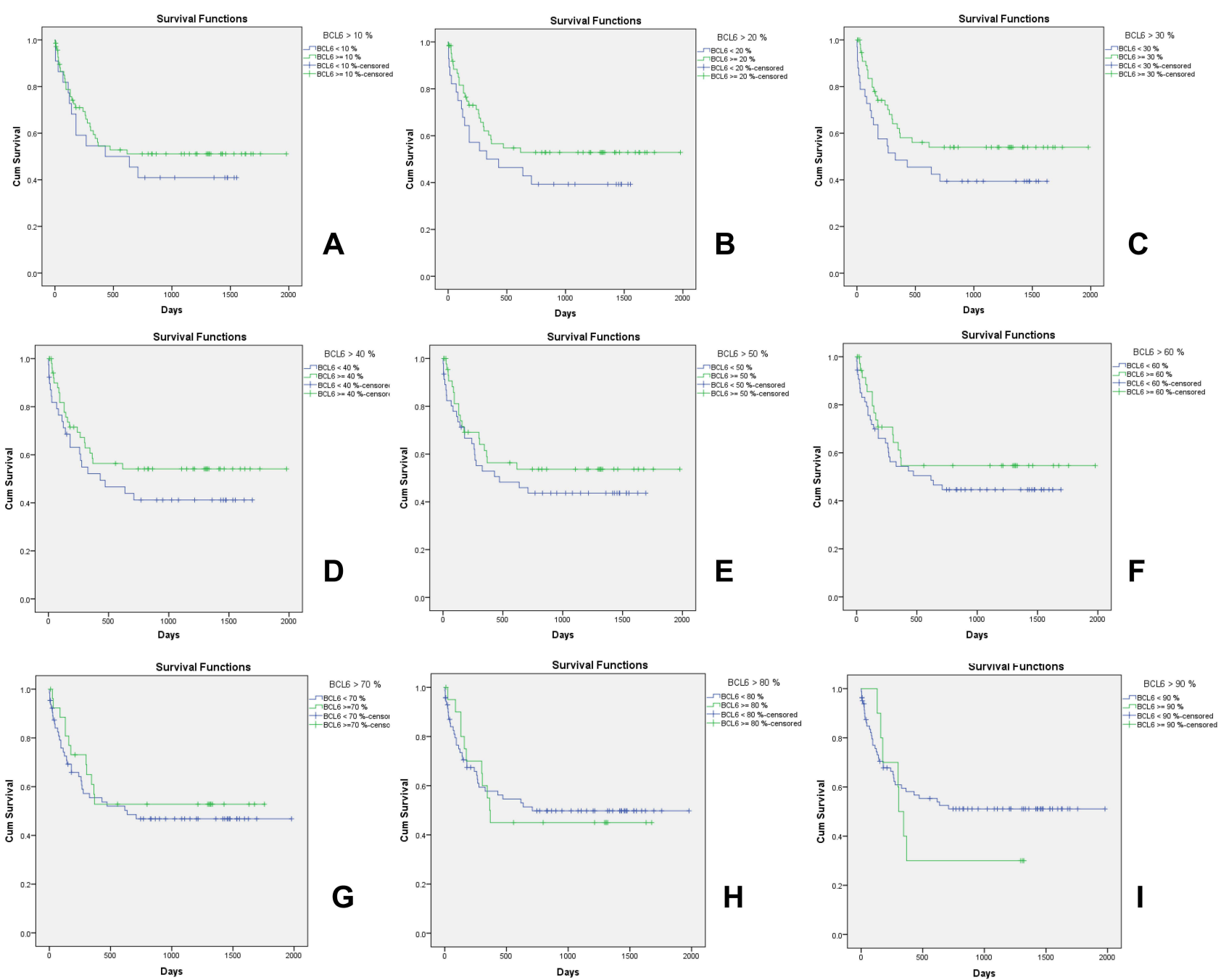

Figure 3 Kaplan-Meier survival curves of BCL6 at 10\% cut-off increments (A) 10\% cut-off (log rank p $=0.445)$ (B) 20\% cut-off (log rank p $=0.195)$ (C) $30 \%$ cut-off (log rank $p=0.1$ I 2) (D) $40 \%$ cut-off $(\log$ rank $p=0.209)(\mathbf{E}) 50 \%$ cut-off $(\log$ rank $p=0.322)(\mathbf{F}) 60 \%$ cut-off $(\log$ rank $p=0.333)(\mathbf{G}) 70 \%$ cut-off $(\log$ rank $p=0.503)(\mathbf{H}) 80 \%$ cut-off (log rank $p=0.916)($ I) $90 \%$ cut-off $(\log$ rank $p=0.424)$.

90\%) (Figures 2-4). However, MUM1 had significant differences in EFS24 between subgroups starting at a 50\% cut-off. The higher the cut-off percentage, the more significant the difference (Figure 5).

\section{Analysis of Age, Gender and IPI Score}

A secondary analysis for Age, Gender, and IPI score was done using Kaplan-Meier survival analysis. There were differences in EFS 24 between Age above or 60 years and under of age $(n=92 ; p=0.014)$, and IPI score high $(>3)$ or low $(n=67 ; p=0.04)$. There was no difference in EFS24 between gender $(n=92 ; p=0.351)$ (Figure 6).

\section{Diagnostic Performance of the Various Proteins and Hans Algorithm}

Using 67 patients with complete set of data, we analyzed each protein expression, IPI category, Age, Gender, and Hans classification to predict events in 24 months using ROC curves. CD10, BCL6, Ki67, and Hans algorithm had AUCs below or near $0.5(0.425,0.43,0.523$, and 0.431 respectively), whereas MUM1 had an AUC of 0.802. The optimal MUM1 cut-off was $71 \%$. At cut-off $<70 \%, 3$ out 24 patients experienced events and at cut-off $\geq 70 \%$, 26 out of 43 patients experienced events. At cut-off 70\%, MUM1 had $86.2 \%$ sensitivity and $60.5 \%$ specificity for predicting the 

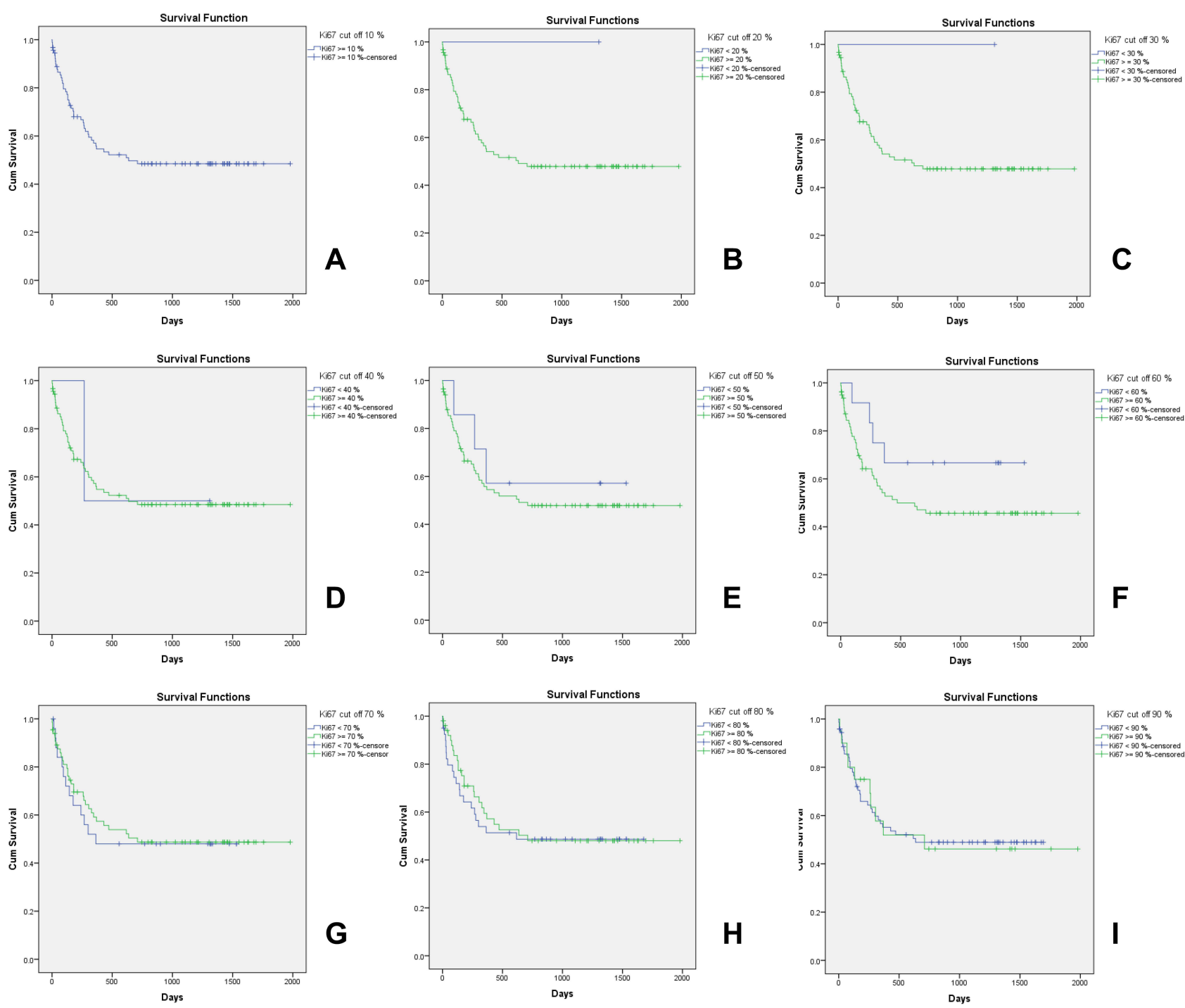

Figure 4 Kaplan-Meier survival curves of Ki67 at 10\% cut-off increments (A) 10\% cut-off (B) $20 \%$ cut-off (log rank p = 0.392) (C) $30 \%$ cut-off (log rank $p=0.392)($ D) $40 \%$ cut-off $(\log$ rank $p=0.87 \mathrm{I})(\mathbf{E}) 50 \%$ cut-off $(\log$ rank $p=0.582)(\mathbf{F}) 60 \%$ cut-off $(\log$ rank $p=0.177)(\mathbf{G}) 70 \%$ cut-off $(\log$ rank $p=0.793)(\mathbf{H}) 80 \%$ cut-off $(\log$ rank $p=0.74 \mathrm{I})$ (I) $90 \%$ cut-off (log rank $p=0.976)$.

occurrence of events. Age $(\mathrm{AUC}=0.616)$, Gender $(\mathrm{AUC}=0.55)$, and IPI score high vs low $(\mathrm{AUC}=0.577)$ were all lower than MUM1 diagnostic performance (Figure 7).

\section{Cox Regression of Various Proteins and Hans Algorithm}

Using Cox regression analysis, we found only MUM1 was significantly associate with event, the HR for each increment of $1 \%$ MUM1 was $1.046(1.024-1.068 ; \mathrm{p}=0.000)$. Using cut-off of $70 \%$, the HR WAS $5.81(2.27-14.85 ; \mathrm{p}=0.000)$ (Table 2).

\section{Discussion}

The use of the Hans algorithm to predict prognostic outcomes in DLBCL patients has had variable results. We observed that the percentage of MUM1 expression was a simpler test and showed promise as a prognostic factor, especially for use in developing countries where a single, immunohistochemical stain might be more cost-effective than multiple ones. 

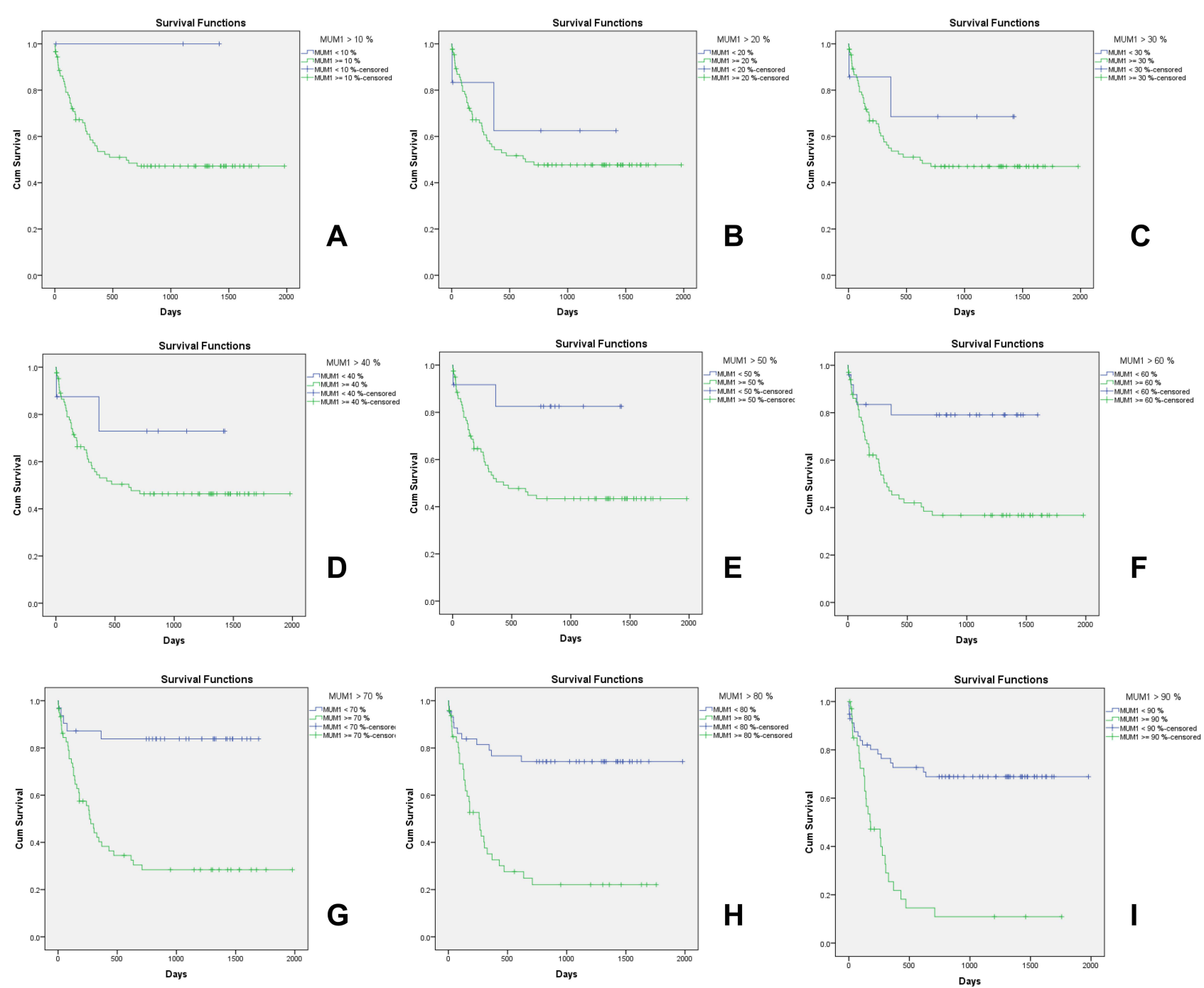

Figure 5 Kaplan-Meier survival curves of MUMI at 10\% cut-off increments (A) $10 \%$ cut-off $(\log$ rank $p=0.216)($ B) $20 \%$ cut-off (log rank p $=0.618)($ C) $30 \%$ cut-off (log rank $p=0.396)(\mathbf{D}) 40 \%$ cut-off $(\log$ rank $p=0.25 \mathrm{I})(\mathbf{E}) 50 \%$ cut-off $(\log$ rank $p=0.035)(\mathbf{F}) 60 \%$ cut-off $(\log$ rank $p=0.003)(\mathbf{G}) 70 \%$ cut-off $(\log$ rank $p=0.000)(\mathbf{H}) 80 \%$ cut-off (log rank $p=0.000)($ I) $90 \%$ cut-off $(\log$ rank $p=0.000)$.
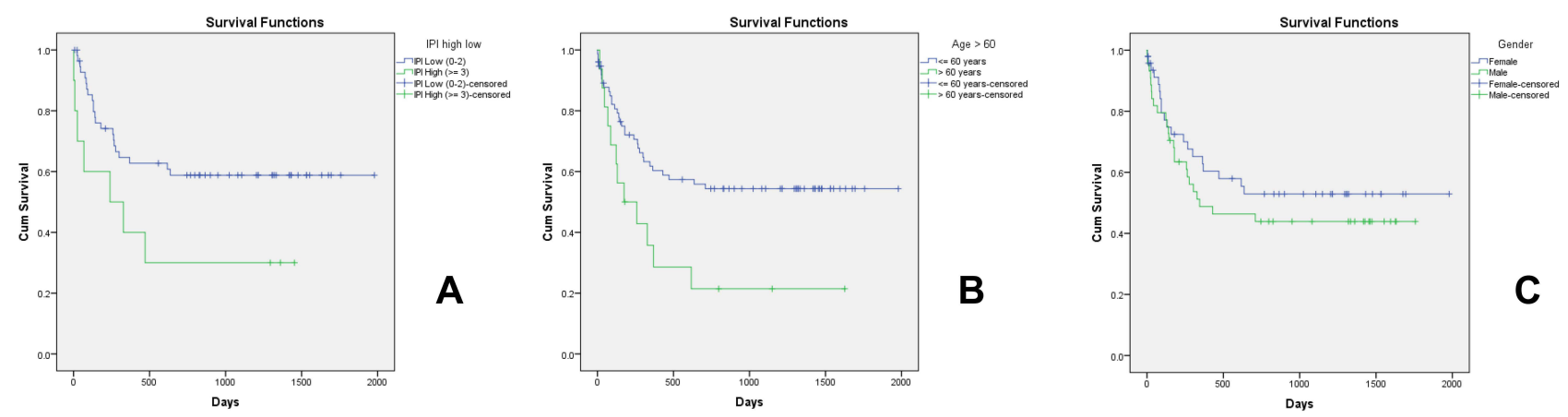

Figure 6 Kaplan-Meier survival curves of IPI (high vs low) $(n=67 ; \log$ rank $p=0.04)$, age $($ old $=>60$ years $)(n=92 ; \log$ rank $p=0.014)$, and gender $(n=92 ; \log$ rank $p=$ $0.35 \mathrm{I})$.

Our subjects' median age was similar to patients from India, ${ }^{27,28}$ but much younger compared to patients from Japan, Korea, China, or Western countries. ${ }^{29}$ The difference might partly be explained by divergent genetic polymorphism, environmental exposure, ${ }^{30,31}$ and earlier age of Epstein-Barr viral infection in developing countries. ${ }^{1}$ 


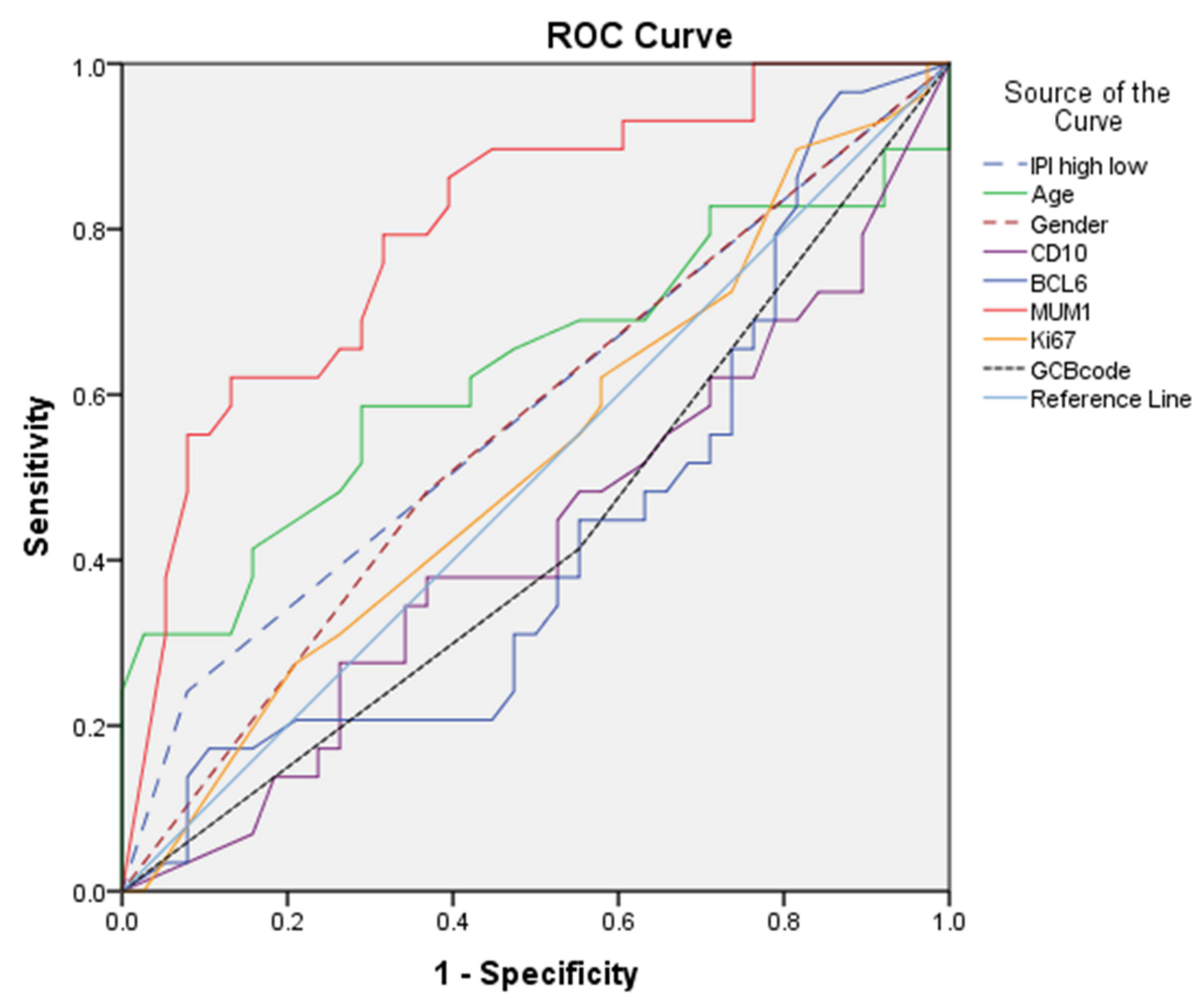

Diagonal segments are produced by ties.

Figure 7 ROC curve from 67 patients; IPI high vs low (AUC $=0.58 \mathrm{I}$ ), age (AUC $=0.63 \mathrm{I})$, gender (AUC $=0.557), C D I 0(A \cup C=0.425), B C L 6(A \cup C=0.43), M U M I(A \cup C$ $=0.802)$, Ki67 (AUC $=0.523)$, GCB subtype $(A \cup C=0.431)$.

The use of a $30 \%$ cut-off for DLBCL protein marker expression was typical in previous studies from other countries, since Hans et al first used this cut-off in 2004. ${ }^{11}$ This cut-off resulted in a wide proportion of cases with $>30 \%$ protein expression. In previous studies, the proportions of subjects with $>30 \%$ protein expression ranged from $9.5 \%$ to $45.9 \%$ for CD10, $28.7 \%$ to $66.9 \%$ for BCL6, and $32 \%$ to $74.4 \%$ for MUM1. ${ }^{11,13,28,32-34}$ In our study, $>30 \%$ CD10, BCL6, and MUM1 expression were noted in $49 \%, 64 \%$, and $92 \%$ of subjects, respectively (Table 1).

Table 2 Prognostic Value of Several Variables for Event Within 24 Months

\begin{tabular}{|l|c|c|}
\hline Variables & $\begin{array}{c}\text { Hazard Ratio (95\% Confidence } \\
\text { Interval) }\end{array}$ & P \\
\hline Model I & $0.764(0.165-3.54 I)$ & 0.73 I \\
GCB (Hans) & $1.000(0.980-1.021)$ & 0.97 I \\
CDI0 (increment I\%) & $0.995(0.986-1.004)$ & 0.308 \\
BCL6 (increment I\%) & $1.046(1.024-1.068)$ & 0.000 \\
MUMI (increment I\%) & $0.987(0.968-1.006)$ & 0.987 \\
Ki67 (increment I\%) & $0.001\left(0.00-2.1 \times 10^{\wedge} 59\right)$ & 0.923 \\
Model 2 & $752.5\left(0.00-2.7 \times 10^{\wedge} 65\right)$ & 0.928 \\
GCB (Hans) & $0.673(0.370-1.227)$ & 0.196 \\
CDI0 (cut off $\geq 30 \%)$ & $5.81(2.27-14.85)$ & 0.000 \\
BCL6 (cut off $\geq 30 \%)$ & $1138.4\left(0.00-1.8 \times 10^{\wedge} 65\right)$ & 0.923 \\
MUMI (cut off $\geq 70 \%)$ & \\
Ki67 (cut off $\geq 30 \%)$ &
\end{tabular}


Using Hans algorithm, $50 \%$ of our cases were GCB subtype, similar to GCB proportions in other Asia or Western countries. ${ }^{28,29,32}$ There was nearly significant difference in EFS24 between the Hans algorithm-based GCB and non-GCB groups ( $\log$ rank $\mathrm{p}=0.08$ ), despite the fact that the GCB subtype tends to have superior outcomes. Even in their original study, immunohistochemistry-based Hans algorithm missed-classified 30 out of 142 patients when compared to cDNA/ gene expression profiles. ${ }^{11}$ The algorithm directly put CD10+ into GCB classification, without looking into BCL6 and MUM1. Our result was also in agreement with a systematic review of previous studies. ${ }^{12}$ However, our small sample size might influence the finding, with more sample we might have more significant difference, or we might find the tendency shift more towards no significance.

CD10, BCL6, and Ki67 expression lacked prognostic value at any cut-off points. Our findings confirmed the results of previously published studies. ${ }^{35-39} \mathrm{CD} 10$ has a complex extracellular and intracellular activity that leads to conflicting prognostic value, and its role in DLBCL needs further studies. ${ }^{40}$ BCL6 and Ki67 protein expression might have lost their prognostic value in the Rituximab era. ${ }^{38,39}$ BCL6 gene rearrangement instead of BCL6 protein expression was found to be associated with prognosis. ${ }^{41}$

However, MUM1 at cut-offs of $50 \%$ or more was a prognostic factor of events within 24 months, as found in previous studies. ${ }^{18,42}$ A MUM1 cut-off of $50 \%$ or more had stronger prognostic value than that of Hans algorithm and other proteins. Using ROC curve, MUM1 had the highest AUC value and could be categorized to have excellent performance (AUC > 0.8) compared to expressions of other proteins and Hans classification. At a 70\% cut-off, in our 92 patients, positive and negative predictive values of MUM1 were $65 \%$ and $84.3 \%$, respectively. An increment of $1 \%$ in MUM1 expression was found to increase 4.6\% hazard for event and MUM1 $\geq 70 \%$ increase 5.8 times hazard for event within 24 months. The importance of MUM1 expression was also shown in a study from China, in which double positive expression cases (CD10 and MUM1) that were categorized as GCB subtype, intriguingly showed inferior prognosis, whereas non-GCB cases with triple negative expression (CD10, BCL6, MUM1), in fact, tended to show superior prognosis. ${ }^{33,43}$ Furthermore, MUM1 showed excellent capability in predicting events in 24 months.

Our data showed that old age ( $>60$ years) and IPI score (high vs low) did give different survival curve, however their diagnostic performance is not as good as MUM1 when we use ROC for EFS 24 months. High IPI had low sensitivity (24.1\%) and high specificity (91.2\%) in predicting EFS24, which translates to better negative predictive value. A low IPI was more likely to have no event, however high IPI does not necessarily predict an event. Similarly, Age $>60$ years had low sensitivity (31\%) and high specificity $(97,1 \%)$. Further analysis showed no correlation of MUM1 positivity with Age and IPI, which encourage MUM1 role in predicting event outside the scope of age and IPI.

Our study limitations were the low number of patients available with complete data, no FISH-analyses were used, and no EBV-status of the tumors, which have been widely known to affect prognosis.

\section{Conclusion}

MUM1 with cut-off of $50 \%$ or more was able to predict the occurrence of death or treatment failure in 24 months for DLBCL patients who underwent R-CHOP regimen. A MUM1 70.5\% cut-off had the optimal trade-off for sensitivity and specificity. Hence, MUM1 might be considered for use as a single marker, as it outperformed Hans algorithm for predicting prognosis within 24 months.

\section{Acknowledgments}

The authors would like to thank all the Hematology - Medical Oncology staff and Anatomic Pathology staff at Cipto Mangunkusumo Hospital for their assistance with this research.

\section{Author Contributions}

All authors made a significant contribution to the work reported, whether that is in the conception, study design, execution, acquisition of data, analysis and interpretation, or in all these areas; took part in drafting, revising or critically reviewing the article; gave final approval of the version to be published; have agreed on the journal to which the article has been submitted; and agree to be accountable for all aspects of the work. 


\section{Disclosure}

The authors report no conflicts of interest in this work.

\section{References}

1. Zucca E, Rohatiner A, Magrath I, Cavalli F. Epidemiology and management of lymphoma in low-income countries. Hematol Oncol. 2011;29(1):14. doi:10.1002/hon.945

2. Intragumtornchai T, Bunworasate U, Wudhikarn K, et al. Non-Hodgkin lymphoma in South East Asia: an analysis of the histopathology, clinical features, and survival from Thailand. Hematol Oncol. 2018;36(1):28-36. doi:10.1002/hon.2392

3. Fisher SG, Fisher RI. The epidemiology of non-Hodgkin's lymphoma. Oncogene. 2004;23(38):6524-6534. doi:10.1038/sj.onc.1207843

4. Gisselbrecht C, Glass B, Mounier N, et al. Salvage regimens with autologous transplantation for relapsed large B-cell lymphoma in the rituximab era. J Clin Oncol. 2010;28(27):4184-4190. doi:10.1200/JCO.2010.28.1618

5. Perry AM, Diebold J, Nathwani BN, et al. Non-Hodgkin lymphoma in the developing world: review of 4539 cases from the International NonHodgkin Lymphoma Classification Project. Haematologica. 2016;101(10):1244-1250. doi:10.3324/haematol.2016.148809

6. Zhou Z, Sehn LH, Rademaker AW, et al. An enhanced International Prognostic Index (NCCN-IPI) for patients with diffuse large B-cell lymphoma treated in the rituximab era. Blood. 2014;123(6):837-842. doi:10.1182/blood-2013-09-524108

7. Alizadeh AA, Eisen MB, Davis RE, et al. Distinct types of diffuse large B-cell lymphoma identified by gene expression profiling. Nature. 2000;403 (6769):503-511. doi:10.1038/35000501

8. Rosenwald A, Wright G, Chan WC, et al. The use of molecular profiling to predict survival after chemotherapy for diffuse large-B-cell lymphoma. N Engl J Med. 2002;346(25):1937-1947. doi:10.1056/NEJMoa012914

9. Lenz G, Wright G, Dave SS, et al. Stromal gene signatures in large-B-cell lymphomas. N Engl J Med. 2008;359(22):2313-2323. doi:10.1056/ NEJMoa0802885

10. Meyer PN, Fu K, Greiner TC, et al. Immunohistochemical methods for predicting cell of origin and survival in patients with diffuse large B-cell lymphoma treated with rituximab. J Clin Oncol. 2011;29(2):200-207. doi:10.1200/JCO.2010.30.0368

11. Hans CP, Weisenburger DD, Greiner TC, et al. Confirmation of the molecular classification of diffuse large B-cell lymphoma by immunohistochemistry using a tissue microarray. Blood. 2004;103(1):275-282. doi:10.1182/blood-2003-05-1545

12. Schmidt-Hansen M, Berendse S, Marafioti T, McNamara C. Does cell-of-origin or MYC, BCL2 or BCL6 translocation status provide prognostic information beyond the International Prognostic Index score in patients with diffuse large B-cell lymphoma treated with rituximab and chemotherapy? A systematic review. Leuk Lymphoma. 2017;58(10):2403-2418. doi:10.1080/10428194.2017.1287364

13. Oh S, Koo DH, Suh C, et al. Prognostic value of immunohistochemical biomarkers at different cut-off values in patients with diffuse large B-cell lymphoma treated with CHOP chemotherapy. J Korean Med Sci. 2011;26(12):1556-1562. doi:10.3346/jkms.2011.26.12.1556

14. Mishra D, Singh S, Narayan G. Role of B cell development marker CD10 in cancer progression and prognosis. Mol Biol Int. 2016;2016:4328697. doi:10.1155/2016/4328697

15. Uherova P, Ross CW, Schnitzer B, Singleton TP, Finn WG. The clinical significance of CD10 antigen expression in diffuse large B-cell lymphoma. Am J Clin Pathol. 2001;115(4):582-588. doi:10.1309/84GE-U85A-FMU0-7AUV

16. LeBien TW, McCormack RT. The common acute lymphoblastic leukemia antigen (CD10)-emancipation from a functional enigma. Blood. 1989;73 (3):625-635. doi:10.1182/blood.V73.3.625.625

17. Cardenas MG, Oswald E, Yu W, Xue F, MacKerell AD, Melnick AM. The expanding role of the BCL6 oncoprotein as a cancer therapeutic target. Clin Cancer Res. 2017;23(4):885-893. doi:10.1158/1078-0432.CCR-16-2071

18. Sofo-Hafizovic A, Chikha A, Gojak R, Hadzimesic ES. Expression IRF/MUM1 $>25 \%$ predictor to three-year survival of diffuse large B cell lymphoma in the immunochemotherapy era. Med Arch. 2016;70(5):342-347. doi:10.5455/medarh.2016.70.342-347

19. Carbone A, Gloghini A, Cozzi MR, et al. Expression of MUM1/IRF4 selectively clusters with primary effusion lymphoma among lymphomatous effusions: implications for disease histogenesis and pathogenesis. Br J Haematol. 2000;111(1):247-257. doi:10.1046/j.1365-2141.2000.02329.x

20. Li LT, Jiang G, Chen Q, Zheng JN. Ki67 is a promising molecular target in the diagnosis of cancer (review). Mol Med Rep. 2015;11(3):1566-1572. doi:10.3892/mmr.2014.2914

21. Iatropoulos MJ, Williams GM. Proliferation markers. Exp Toxicol Pathol. 1996;48(2-3):175-181. doi:10.1016/S0940-2993(96)80039-X

22. Babu G, Lakshmaiah K, Dasappa L, et al. Ki-67 and subtype as prognostic and predictive markers of diffuse large B-cell lymphoma. Clin Cancer Investigat J. 2017;6(1):97-102. doi:10.4103/ccij.ccij_12_17

23. Li ZM, Huang JJ, Xia Y, et al. High Ki-67 expression in diffuse large B-cell lymphoma patients with non-germinal center subtype indicates limited survival benefit from R-CHOP therapy. Eur J Haematol. 2012;88(6):510-517. doi:10.1111/j.1600-0609.2012.01778.x

24. Hasselblom S, Ridell B, Sigurdardottir M, Hansson U, Nilsson-Ehle H, Andersson PO. Low rather than high Ki-67 protein expression is an adverse prognostic factor in diffuse large B-cell lymphoma. Leuk Lymphoma. 2008;49(8):1501-1509. doi:10.1080/10428190802140055

25. He X, Chen $\mathrm{Z}, \mathrm{Fu} \mathrm{T}$, et al. Ki-67 is a valuable prognostic predictor of lymphoma but its utility varies in lymphoma subtypes: evidence from a systematic meta-analysis. BMC Cancer. 2014;14:153. doi:10.1186/1471-2407-14-153

26. de Jong D, Rosenwald A, Chhanabhai M, et al. Immunohistochemical prognostic markers in diffuse large B-cell lymphoma: validation of tissue microarray as a prerequisite for broad clinical applications-a study from the Lunenburg Lymphoma Biomarker Consortium. J Clin Oncol. 2007;25 (7):805-812. doi:10.1200/JCO.2006.09.4490

27. Gogia A, Das CK, Kumar L, et al. Diffuse large B-cell lymphoma: an institutional analysis. South Asian J Cancer. 2018;7(3):200-202. doi:10.4103/ sajc.sajc_65_18

28. Dwivedi A, Mehta A, Solanki P. Evaluation of immunohistochemical subtypes in diffuse large B-cell lymphoma and its impact on survival. Indian J Pathol Microbiol. 2015;58(4):453-458. doi:10.4103/0377-4929.168886

29. Castillo JJ, Sinclair N, Beltran BE, et al. Similar outcomes in Asian and Western patients with diffuse large B-cell lymphoma treated with R-CHOP. Leuk Res. 2013;37(4):386-391. doi:10.1016/j.leukres.2013.01.002

30. Zhao H, Kan Y, Wang X, Chen L, Ge P, Qian Z. Genetic polymorphism and transcriptional regulation of CREBBP gene in patient with diffuse large B-cell lymphoma. Biosci Rep. 2019;39:8. doi:10.1042/BSR20191162 
31. Ng CJ, Teo CH, Abdullah N, Tan WP, Tan HM. Relationships between cancer pattern, country income and geographical region in Asia. BMC Cancer. 2015;15:613. doi:10.1186/s12885-015-1615-0

32. Berglund M, Thunberg U, Amini RM, et al. Evaluation of immunophenotype in diffuse large B-cell lymphoma and its impact on prognosis. Mod Pathol. 2005;18(8):1113-1120. doi:10.1038/modpathol.3800396

33. Lu TX, Miao Y, Wu JZ, et al. The distinct clinical features and prognosis of the CD10(+)MUM1(+) and CD10(-)Bcl6(-)MUM1(-) diffuse large B-cell lymphoma. Sci Rep. 2016;6:20465. doi:10.1038/srep20465

34. Chang CC, McClintock S, Cleveland RP, et al. Immunohistochemical expression patterns of germinal center and activation B-cell markers correlate with prognosis in diffuse large B-cell lymphoma. Am J Surg Pathol. 2004;28(4):464-470. doi:10.1097/00000478-200404000-00005

35. Colomo L, Lopez-Guillermo A, Perales M, et al. Clinical impact of the differentiation profile assessed by immunophenotyping in patients with diffuse large B-cell lymphoma. Blood. 2003;101(1):78-84. doi:10.1182/blood-2002-04-1286

36. Xu Y, McKenna RW, Molberg KH, Kroft SH. Clinicopathologic analysis of CD10+ and CD10- diffuse large B-cell lymphoma. Identification of a high-risk subset with coexpression of CD10 and bcl-2. Am J Clin Pathol. 2001;116(2):183-190. doi:10.1309/J7RN-UXAY-55GX-BUNK

37. Fabiani B, Delmer A, Lepage E, et al. CD10 expression in diffuse large B-cell lymphomas does not influence survival. Virchows Arch. 2004;445 (6):545-551. doi:10.1007/s00428-004-1129-7

38. Winter JN, Weller EA, Horning SJ, et al. Prognostic significance of Bcl-6 protein expression in DLBCL treated with CHOP or R-CHOP: a prospective correlative study. Blood. 2006;107(11):4207-4213. doi:10.1182/blood-2005-10-4222

39. Jerkeman M, Anderson H, Dictor M, et al. Assessment of biological prognostic factors provides clinically relevant information in patients with diffuse large B-cell lymphoma-a Nordic Lymphoma Group study. Ann Hematol. 2004;83(7):414-419. doi:10.1007/s00277-004-0855-x

40. Maguer-Satta V, Besancon R, Bachelard-Cascales E. Concise review: neutral endopeptidase (CD10): a multifaceted environment actor in stem cells, physiological mechanisms, and cancer. Stem Cells. 2011;29(3):389-396. doi:10.1002/stem.592

41. Li S, Wang Z, Lin L, et al. BCL6 rearrangement indicates poor prognosis in diffuse large B-cell lymphoma patients: a meta-analysis of cohort studies. J Cancer. 2019;10(2):530-538. doi:10.7150/jca.25732

42. De Mello CA, De Andrade VP, De Lima VC, Carvalho AL, Soares FA. Prognostic impact of MUM1 expression by immunohistochemistry on primary mediastinal large B-cell lymphoma. Leuk Lymphoma. 2011;52(8):1495-1503. doi:10.3109/10428194.2011.573032

43. Ichiki A, Carreras J, Miyaoka M, et al. Clinicopathological analysis of 320 cases of diffuse large B-cell lymphoma using the Hans classifier. $J$ Clin Exp Hematop. 2017;57(2):54-63. doi:10.3960/jslrt.17029

\section{Publish your work in this journal}

Cancer Management and Research is an international, peer-reviewed open access journal focusing on cancer research and the optimal use of preventative and integrated treatment interventions to achieve improved outcomes, enhanced survival and quality of life for the cancer patient. The manuscript management system is completely online and includes a very quick and fair peer-review system, which is all easy to use. Visit http://www.dovepress.com/testimonials.php to read real quotes from published authors. 